инвестиционный рынок представляет собой многоуровневую разветвленную систему взаимодействия различных рынков и их сегментов.

$* * *$

1. Бочаров, В.В. Инвестиции. - $\quad$ СПб.: Питер, $2005 . \quad$ // https://www.biznesbooks.com/components/com_jshopping/files/demo_products/bocharov-v-v-investitsii.pdf (дата обращения 25.11.2021)

2. Иванов, Г.И. Инвестиции: сущность, виды, механизмы функционирования. -Ростов н/Д: Феникс, 2007. // https://search.rsl.ru/ru/record/01002555237 (дата обращения 28.11.2021)

3. Инвестиции: Терминологический словарь. - М.: ИНФРА-М, 2007.

\title{
Исина А.А.-к. \\ Цифровой маркетинг как фактор повышения экономической эффективности гостиниц
}

Евразийский Начиональный Университет им.Л.Н.Гумилева (Казахстан, Нур-Султан)

doi: 10.18411/trnio-01-2022-91

Научный руководитель: Балгабаева В.T.

\section{Аннотация}

Цифровой маркетинг - это продвижение товаров или брендов через Интернет. В последние дни спрос на цифровой маркетинг в отелях становится все более высоким благодаря маркетингу в социальных сетях (SMM), который работает с сайтами социальных сетей, и поисковой оптимизацией (SEO), благодаря чему веб-сайт появляется в результатах поиска с рекламой в Google и онлайн-журналах от маркетинга в поисковых системах (SEM), видеомаркетинг через YouTube и веб-сайты - это разновидности цифрового маркетинга. Поиск отелей в Интернете с помощью компьютеров и мобильных устройств с помощью вебсайтов отелей - это новая тенденция цифрового маркетинга, которая дает возможность улучшить местную поиск отелей путем предоставления необходимого контента, профилей пользователей, управления цитированием и в результатах поиска. Цель - изучить роль цифрового маркетинга в гостиничном бизнесе. Эта статья также направлена на определение того, какой тип цифрового маркетинга лучше всего подойдет для гостиничного бизнеса.

Ключевые слова: поисковая оптимизация (SEO), маркетинг в поисковых системах (SEM), маркетинг в социальных сетях (SMM), видео маркетинг, система управления недвижимостью (PMS), глобальная система распределения (GDS), центральная система бронирования (CRS).

\section{Abstract}

Digital marketing is the promotion of products or brands via the Internet. In recent days, the demand for digital marketing in hotels has become increasingly high thanks to social media marketing (SMM), which works with social media sites, and search engine optimization (SEO), thanks to which a website appears in search results with ads in Google and online magazines from search engine marketing (SEM), video marketing via YouTube and websites are varieties of digital marketing. Searching for hotels on the internet using computers and mobile devices using hotel websites is a new digital marketing trend that makes it possible to improve local hotel search by providing the necessary content, user profiles, citation management and in search results. The goal is to study the role of digital marketing in the hotel business. This article also aims to determine which type of digital marketing is best suited for the hotel business.

Keywords: search engine optimization (SEO), search engine marketing (SEM), social media marketing (SMM), video marketing, real estate management system (PMS), global distribution system (GDS), central booking system (CRS). 


\section{1. Введение.}

Цифровой маркетинг произвел заметные изменения в маркетинге индустрии и открыли новые каналы для продажи продуктов, таких как маркетинг в социальных сетях (SMM) через Интернет и мобильные приложения, поисковая оптимизация (SEO) для рекламы в Google и онлайн-журналах с помощью маркетинга в поисковых системах (SEM) конкуренция со стороны посредников, таких как туристические агенты, на данный момент туроператоры присутствуют во всех отелях, потому что они являются одним из источников, которые приводят гостей в отель с помощью своих рекламных носителей и их поведения при определении поиска клиентов в зависимости от местоположения и возможностей, исходя из интенсивности рыночной конкуренции [1], онлайн-видео через YouTube отели могут рекламировать свои услуги, точно показывая свои номера, рестораны, банкетный зал, спа, фитнес-центр, бар, кафе и т.д. Расширение источника, чтобы стать более знакомым и понятным на сайтах социальных сетей с помощью лучшего видео с удобствами на веб-сайте отеля, улучшает контент для просмотра и чтения для онлайн-посетителей, частые посещения, стремление к значительному лучшему росту веб-сайта. В дополнении, необходимо получить более полное представление о расположении отеля и удобствах. Отели заинтересованы в том, чтобы предпринять необходимые шаги, для настройки своего подхода к взаимодействию с гостями, чтобы развить новую маркетинговую компетенцию, и это будет полезно для повышения уровня каждого индивидуального гостя [2]. Зная потребности клиентов бренды становятся менее влиятельными по мере того, как клиенты получают информации через Интернет. В ресторанах отеля должны указываться специальное блюдо дня в меню, а затем сниматься видео о приготовлении пищи, выполняемой шеф-поваром, добрачной представить специальные блюда отеля и сделать короткое предложение во время например сезонного отдыха, чтобы эти блюда были доступны в меню отеля в течение короткого периода. Это является правильным способом продвижения отеля в Интернете для потенциальных клиентов.

\section{2. Методология.}

В методологии были использованы качественные и количественные методы исследования. собрать данные для этого исследования. В отеле в целях исследования было распределено 50 анкет и это случайным образом, но только 40 были заполнены и использованы для анализа. Это исследование проводилось с мая по январь 2017 года в пятизвездочных отелях в Ченнаи. Статистический пакет для социальных наук (версия SPSS 21) и AMOS использовались для анализа данных, а вторичные данные были собраны с помощью литературного обзора.

\section{Социальный медиа маркетинг.}

Социальные сети служат мостом для маркетинга продуктов и услуг для различных типов организаций и компаний по всему миру с помощью мобильных телефонов, facebook, twitter, блогов, Google+, LinkedIn, Instagram, YouTube. Он работает, привлекая контент или по таргетированной рекламе потенциальному клиенту показывает необходимый контент, также нельзя забывать об информации представленный на веб-сайте, на сайтах социальных сетей с помощью привлекающего контента, он побуждает читателей делиться своими взглядами в социальной сети, предоставляя информацию об организациях, учреждениях и компаниях потенциальным потребителям, в свою очередь SMM предоставляет продавцам информацию о потребителях. В гостиничной индустрии социальные сети стали источником маркетинга их продуктов, таких как номера, завтрак, обед и ужин «шведский стол», спа и другие услуги для потребителей. Социальные сети служат мостом между пользователями и посетителями или зрителями, а также помогают во взаимодействии друг с другом через Интернет для обмена информацией и мнениями об отеле. Сетевые интернет-сайты, такие как Instagram, Twitter и Facebook, распространились на все отели класса люкс с целью рекламы и оценки, что, в свою очередь, помогает в расширении бизнес-возможностей [3]. Отели должны найти новую форму технологий, которые помогут поддерживать присутствие отеля 
в социальных сетях, а также в онлайн-компаниях для увеличения и поддержки продаж отелей [4].

\section{Поисковая оптимизация (SEO).}

Оптимизация веб-сайта отеля поможет улучшить гостиничный бизнес. Это метод попадания веб-сайта в результаты поисковой системы, и этот процесс работает с ключевыми словами и с частотой веб-сайта в списках поисковых систем. Веб-сайт имеет более высокий рейтинг по количеству посетителей, часто посещаемых веб-сайтом на странице результатов поиска и по тому, сколько раз сайт появляется в списке результатов поиска. Это поможет привлечь больше посетителей на ваш сайт, и SEO сможет фокусироваться на различных типах поиска, включая поиск по словам, локальный поиск, поиск видео, поиск изображений, институциональный поиск, расположение в отеле, удобства и некоторые новости, связанные с отелем будет генерировать трафик на веб-сайт отеля, а также работать не без помощи инструментов SEM, где посещаемость веб-сайта возрастет. У каждого отеля должен быть веб-сайт, и это становится необходимым для того, чтобы сделать отель видимым в Интернете, и основная цель этого веб-сайта - привлечь посетителей на определенный вебсайт отеля с помощью онлайн-инструментов [5].

\section{Видеомаркетинг.}

Для получения качественного и эффективного видеомаркетинга, необходимо идентифицировать через какие средства массовой информации вы хотите сосредоточиться. Самое приятное - это добавление видеороликов на веб-сайт отеля, чтобы выделить и повысить популярность, и онлайн-посетители всегда предпочтут оставаться на веб-сайте надолго только тогда, когда на веб-сайте есть видео, связанное с их поиском, и это также улучшает качество веб-сайта, отели не будут иметь надлежащее взаимодействие с гостем для предоставления точной и своевременной информации без веб-сайта, а также отель не упустит потенциального гостя, не имея надлежащих фотографий и видео отеля. Работникам гостиниц разрабатывающий маркетинговых планов будет полезным размещение видеороликов на сетевых сайтах, чтобы продвигать свои позиции и привлекать внимание гостей и получать от этого феноменальную выгоду (Вирджиния Фелан Келли, Чен Сян-Тинг, Хэни Мэтью, 2013). В отеле можно снять видео со своими уникальными удобствами, декором, атмосферой и фирменными блюдами. Видеоролики, созданные маркетологами гостиниц, необходимо обновлять каждый год, и это улучшит статус отеля с точки зрения тенденций цифрового маркетинга, а также при разработке маркетинговых стратегий.

\section{Системы управления недвижимостью (PMS).}

PMS, это комплексное программное приложение, используемое для выполнения основных задач отеля и управление этим имуществом. Системы не только хранят и обмениваются данными об отелях, они также действуют как мост в цифровом маркетинге для гостиниц, принимая бронирование через веб-сайт со скидками и предложениями и отправляя автоматические письма с подтверждением гостю. Это важный инструмент в развитии гостиничного бизнеса с помощью глобальных распределительных систем, которые работают удаленно (GDS), другой - систем распространения через Интернет (IDS) представляющих веб-сайт гостиниц, а центральные системы бронирования (CRS) помогают в резервировании номеров. гостиничных номеров по всему миру. GDS это программное обеспечение помогающее в сборе, обработке и пересылке информации, созданной гостем, о гостинице, для оптимизации работы. Sabre - это самая лучшая и самая известная во всем мире GDS. Наибольшее влияние на веб-сайт отеля оказывают IDS и продаёт номер с ночевкой на комиссионной основе, добавочно помогает в сборе сведений о гостях при бронировании и напрямую подключается к системе управления недвижимостью через GDS. Самое главное, что эффективная система управления недвижимостью или гостиницы становится еще более полезной для доступа к данным из все большего числа источников для отелей. Большие объемы данных, генерируемых в социальных сетях, таких как Facebook, Instagram, Whatsapp и Twitter, могут раскрыть бесценную информацию об отношении и предпочтениях клиентов по отношению к их продукту. Отели могут использовать аналитику 
больших данных для категоризации данных и получения ценных сведений об отношении потребителей к их фирмам и организациям-конкурентам. Наличие системы управления недвижимостью (PMS), которая объединяет KM, социальные сети и технологию больших данных, позволяет компаниям лучше извлекать, хранить и использовать знания более эффективно. На рынке доступно множество систем управления недвижимостью, которые могут быть спроектированы в соответствии с размером и типом отеля, но не все отели можно купить из-за их высокой стоимости.

\section{3. Обсуждение.}

Поисковые системы играют основную роль в развитии отелей. В 2021 году бизнес развивается с помощью оптимизации веб-сайты отелей с видеороликами и изображениями об их объектах, местонахождении и группе, с которыми они работают по франшизе, также бизнес получают данные от авиакомпаний, туроператоров и турагентов со своими вебсайтами. Результаты основаны на интерпретации данных, собранных отелями Нур-Султана.

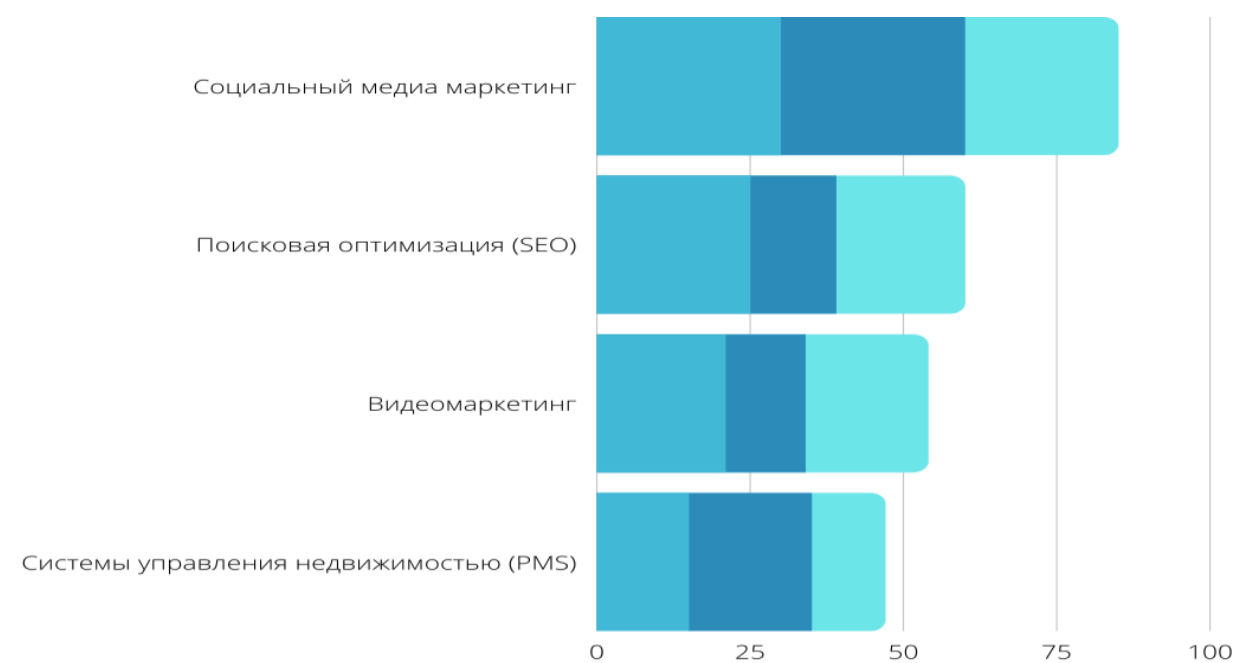

Рисунок 1. Популярность сочииального медиа маркетинга (SMM), поисковой оптимизащии (SEO), видео маркетинга и системы управления недвижимостью (PMS) среди отелей в городе Нур-Султан. Источник: собственная обработка

\section{4. Результаты.}

По словам [6] после завершения создания вашего веб-сайта вам необходимо отправить его в каталоги поисковых систем, где он должен быть легко найден вашими клиентами и потенциальными клиентами. Важный фактор - наименование бренда, в нашем случае гостиницы или отеля, и обязательно отображение названия во многих поисковых системах, насколько это возможно. Кто знает, какой каталог и поисковая система предпочитает ваш потенциальный посетитель? Когда люди проводят поиск в Интернете, они редко выходят за рамки первых нескольких страниц результатов. Чтобы вас заметили, нужно попасть в топ-20 результатов поиска. [7] Отель - это место, которое претерпело значительные изменения за последние два десятилетия с появлением компьютеров. Интернет растет настолько быстро, что людям теперь легче планировать свой отпуск онлайн, чем лично. Компьютеры используются в отелях по разным причинам. В передней части отеля компьютеры оснащены высокотехнологичным программным обеспечением PMS. PMS отеля может взаимодействовать с веб-сайтами, используемыми для бронирования гостей и онлайнбронирования [8]. Информационные технологии создали новую среду во взаимоотношениях с продажей гостиничных продуктов. Гости могут легче получать качественную информацию о своих желаемых интересах с помощью цифровых технологий. Оптимизация стала для отеля основной задачей, а теперь и необходимостью, использование мобильных приложений связано с веб-сайтом и совместимо с системой мобильного бронирования. В последнее время количество бронирований со смартфонов резко возросло [9]. Большинство пользователей Интернета заявляют, что они используют поисковую систему, чтобы найти необходимую 
информацию об отеле. Если отель не зарегистрирован в поисковой системе, вам может быть сложно найти потенциального гостя, ведь не все знают наизусть веб-адрес своих любимых гостиниц.

Интернет-маркетинг осуществляется в несколько этапов. Операция начинается с формулирования бизнес-стратегии, затем продолжается получение информации о рыночных возможностях, формулирование и разработка маркетинговой стратегии только с учетом опыта гостя, разработка маркетинговой программы путем разработки клиентского интерфейса и оценка маркетинговой программы как целое. Сила онлайн-сетей за счет нацеливания на основной источник, такой как электронная почта и веб-контент, с использованием баз данных, и есть возможность эффективно отслеживать рекламу, длина сообщения, и сайты, социальные сети являются одним из основных источников выйти на международный рынок одним сообщением.

\section{5. Выводы.}

Преимущество цифрового маркетинга - низкая стоимость и хорошее

рекламные материалы. Часто оптимизируя сайт отеля можно получить лучший гостиничный бизнес. По этому методу сайт отеля появляется в результатах поисковой системы и будет ранжироваться в соответствии с частотой. Видео - хороший источник цифрового маркетинга в гостиничном бизнесе. Если в отеле есть рекламный видеоролик, который можно предварительно сделать с помощью трубки и Instagram, специалисту по маркетингу отеля необходимо снять видеоролик с маркетинговой стратегией в соответствии с собственностью отеля. В выходные дни проводить видеосъёмку отеля, в котором можно выделить ресторан со специальным дневным меню, а также интервью с шеф-поваром отеля о фирменных блюдах отеля и способах их приготовления на кухне. Зная требования отеля необходимо выбрать самый соответственный PMS и совместимый с онлайн работой отеля, это является важной задачей, потому что он помогает получить и поддерживать номера всегда занятыми, исполнять работу с помощью веб-сайта отеля.

$$
* * *
$$

1. Wang Z \& Kim HG, "Can social media marketing improve customer relationship capabilities and firm performance? Dynamic capability perspective", Journal of Interactive Marketing, Vol.39, (2017), pp.15-26. - статья

2. Kim AJ \& Ko E, "Impacts of luxury fashion brand's social media marketing on customer relationship and purchase intention", Journal of Global Fashion Marketing, Vol.1, No.3, (2010), pp.164- 171. - статья

3. Inversini A \& Masiero L, "Selling rooms online: the use of social media and online travel agents", International Journal of Contemporary Hospitality Management, Vol.26, No.2, (2014), pp.272-292. - статья

4. Quinton S \& Khan MA, "Generating website traffic: a new model for SMEs", Direct Marketing: An International Journal, Vol.3, No.2, (2009), pp.109-123. - статья

5. Virginia Phelan K, Chen HT \& Haney M, "Like" and "Check-in": how hotels utilize Facebook as an effective marketing tool. Journal of hospitality and Tourism Technology, Vol.4, No.2, (2013), pp.134-154. - статья

6. Kasavana ML \& Brooks RM, Managing Front Office Operations (7th Edition), (2005) - статья

7. Susan Sweeney, Internet Marketing for tourism business, Maximum Press, (2005). - статья

8. $\quad$ Wind J \& Mahajan V, Digital marketing, 2001.-книга

9. Chaffey D \& Smith PR, E-marketing excellence, Planning and Optimizing your, (2008).-книга

\section{Каюшкин Н.Д., Дружинин М.О. \\ Статистический анализ развития науки в Российской Федерации}

Государственный университет управления

(Россия, Москва)

doi: 10.18411/trnio-01-2022-92

Научный руководитель: Долгих Е.А.

\section{Аннотация}

Статья посвящена анализу Российской науки. Авторами были изучены ключевые показатели, которые показывают её фактическое состояние. Актуальность данной работы заключается в методологии исследования и определении ключевых проблем науки в России.

Ключевые слова: наука, исследования и разработки, внутренние затраты, региональные различия, профессиональная мобильность. 